\title{
A case of subconjunctival dirofilariasis in South India
}

\author{
Savita Bhat • Ovi Sofia • M. Raman • Jyotirmay Biswas
}

Received: 10 March 2012 / Accepted: 26 April 2012 /Published online: 11 May 2012

(C) The Author(s) 2012. This article is published with open access at SpringerLink.com

\begin{abstract}
We describe a case of subconjunctival dirofilariasis from South India. The worm was identified by detailed morphologic study.
\end{abstract}

Keywords Subconjunctival dirofilariasis · Dirofilaria tenuis

A 75-year-old male presented with redness and irritation of the left eye. Ophthalmic examination revealed a thin white live worm wriggling around superior conjunctiva. The worm removal was done under local anesthesia and identified as an adult female Dirofilaria tenuis. D. tenuis rarely causes subconjunctival dirofilariasis in Asia. The parasite was identified by detailed morphologic study in wet preparation. Dirofilaria is identified by filariform; body cuticle is finely striated. Mouth without lips and

Electronic supplementary material The online version of this article (doi:10.1007/s12348-012-0078-6) contains supplementary material, which is available to authorized users.

\section{S. Bhat}

Giridhar Eye Institute,

Kochi, India

O. Sofia

Department of Ophthalmology, Saiful Anwar General Hospital, Brawijaya University,

Malang, Indonesia

M. Raman

Department of Parasitology, Madras Veterinary College,

Chennai, India

\section{J. Biswas $(\triangle)$}

Department of Uveitis and Ocular Pathology,

Sankara Nethralaya,

Chennai, India

e-mail: drjb@snmail.org

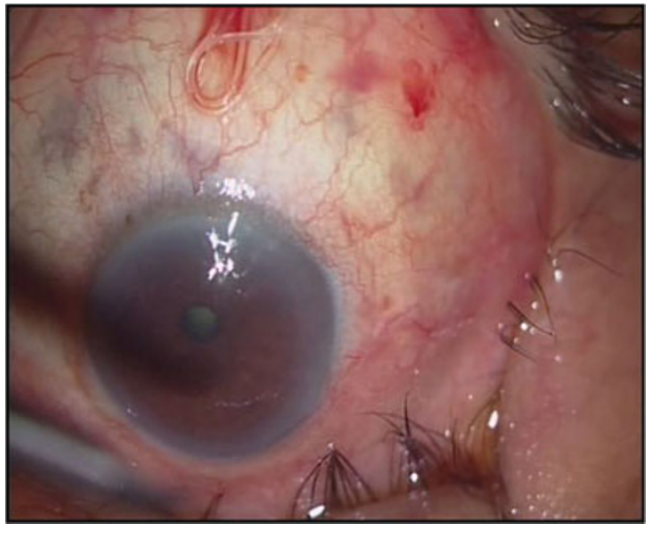

Fig. 1 Photograph of left eye showing the live worm in superior conjunctiva

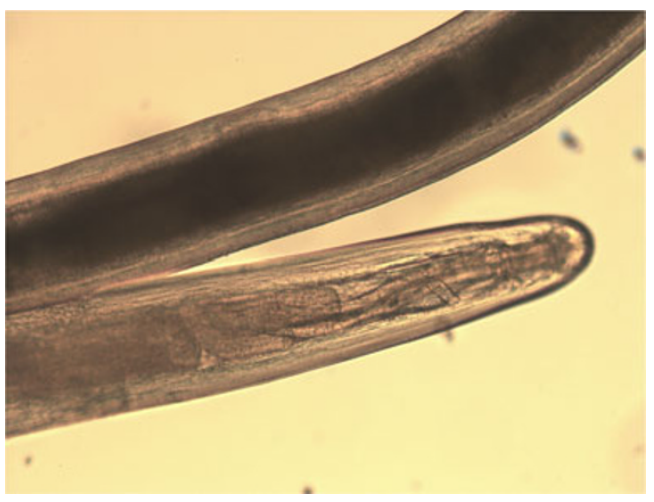

Fig. 2 Anterior end of adult female D. tenuis $(\times 10)$ 


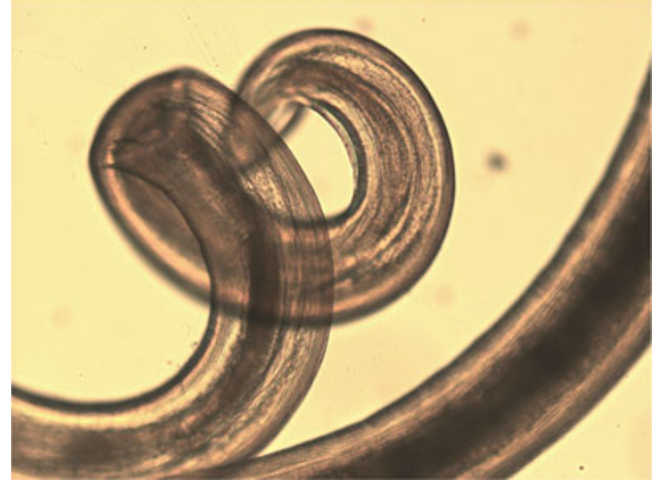

Fig. 3 Posterior end of adult female $D$. tenuis $(\times 10)$. Posterior end is rounded and vulva is little behind the esophagus encircled by six to ten papillae and head papillae are insignificant. Esophagus is relatively short and very distinctly divided into two portions - muscular and ventricular (Figs. 1, 2, and 3). The identification of the parasite can also be done using polymerase chain reaction technique.

Open Access This article is distributed under the terms of the Creative Commons Attribution License which permits any use, distribution and reproduction in any medium, provided the original author(s) and source are credited. 